\title{
Perchance to Read: Developing an Augmented Reality Game to Increase Student Engagement with Hamlet
}

\author{
John Misak, New York Institute of Technology \\ Kevin LaGrandeur, New York Institute of Technology
}

\begin{abstract}
Modern students often learn with a technology-first attitude. ${ }^{1}$ At the same time, many students, particularly those in STEM majors, view reading complex literary texts like Hamlet as both difficult and unappealing. ${ }^{2}$ Given the former, we envisioned a way to alleviate the latter with technology. We based our theory, that technology can serve as an entryway into literary analysis, close reading, and the historical context of the play, on existing research in digital humanities, extended reality (AR/VR) in education, and traditional Shakespeare pedagogy. We sought to improve upon common technologies already in the classroom, namely audio and film clips, by creating an immersive, interactive application that would encourage subsequent reading, thereby tying twenty-first century teaching methods with traditional learning objectives. This article will outline the application development process and how pedagogy, learning outcomes, student feedback, and beta testing informed the design, scene/text selection, and ultimately, the technological platform we chose to use. Hamlet contains dense historical and cultural contexts we intended to impart to students, so choosing scenes required careful consideration. Inspired by Shakespeare pedagogies that seek to involve students directly in the play, along with knowledge of the benefits of high-impact practices, we expected to create an application that melded these elements.
\end{abstract}

Our application creates a technological intervention to encourage traditional reading as opposed to replacing it. Although our game is still in development, our beta tests of the prototypes have shown that students' engagement with and understanding of the play is increased with the immersiveness of Augmented Reality (AR) and by their enthusiasm for the video gaming format and its goal-oriented structure. Despite some technological obstacles, we observed a marked increase in student discussion after the game compared to using standard lectures or showing video clips. We also noted an incidental increase in collaborative activity between students, as the game encouraged them to help each other solve the questions it posed. 


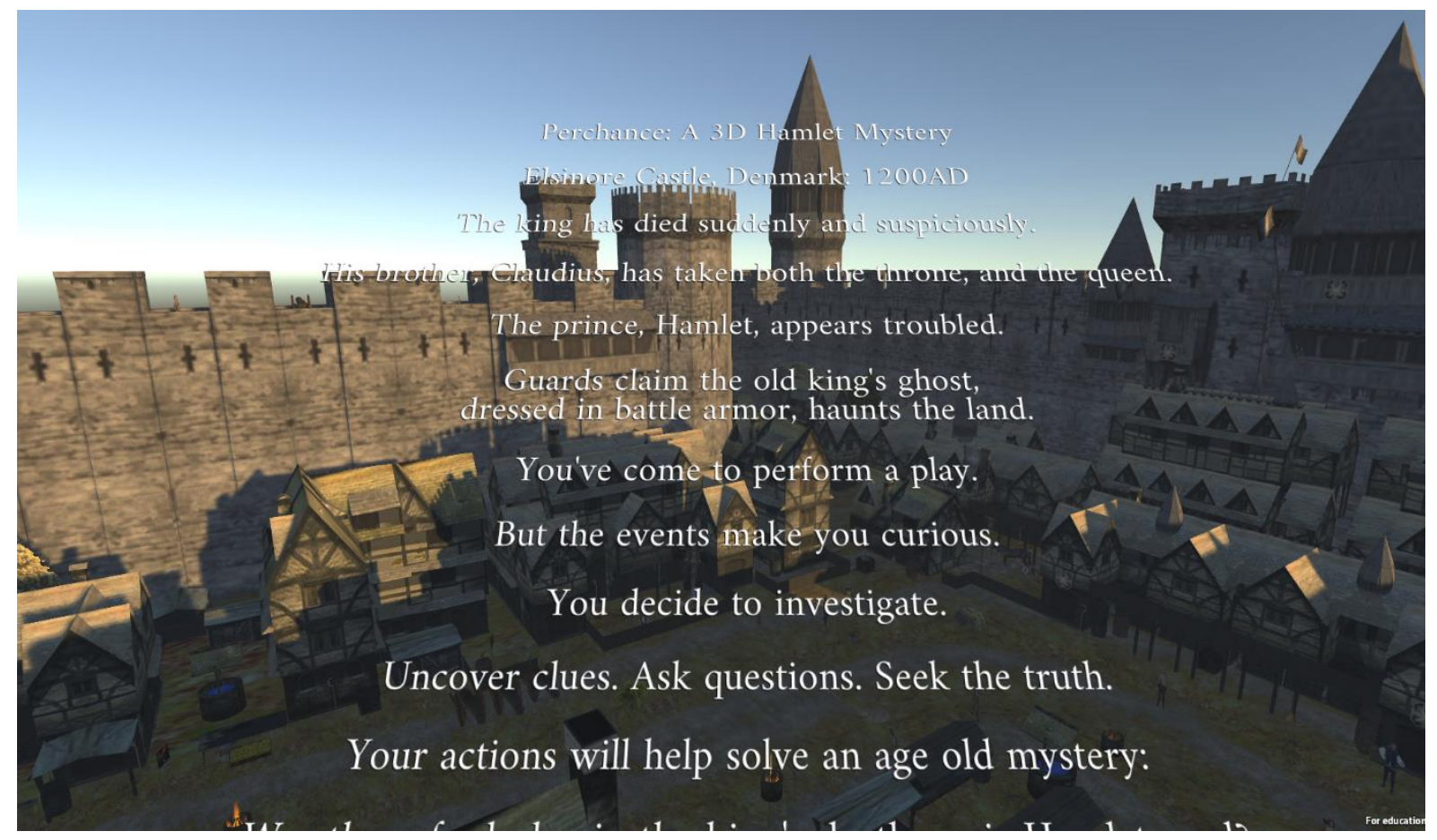

Figure 1. The game's opening text crawl. The goal was to give student-players a purpose to the game without leading them too much.

We anticipate that further experimentation could provide other promising avenues for literary studies and the humanities.

\section{Project Overview and Goals}

Mobile application/game design is an iterative process involving constant restructuring and testing. Given our goals and audience, we decided it was best to involve students in the process immediately. We interviewed instructors and students, seeking areas of concern we could address with our project. After this discovery phase, we focused on the historical and cultural contexts of this play. Instructors found the process of teaching these contexts time consuming and our research indicated, "educational innovation often occurs [...] when "old" ways of teaching $[\ldots]$ become unfit for purpose and/or unsustainably demanding on faculty time" (Thew 15). Context is often delivered via lecture. Based on our research referenced above, we felt active learning would improve the success of conveying these contexts and save instruction time. We investigated the efficacy of technologies like AR and VR - ones that have seen success in STEM applications - in humanities education, where few such projects exist. Since a large portion of 
our test group included STEM majors, we expected the familiarity of the technologies would aid in context instruction through our application.

We will outline our research into and ultimate dismissal of VR for these purposes. Much evidence points to VR's efficacy in classroom environments and the technology may have a place in the future of the humanities classroom, but not for our purpose. Therefore, our application incorporated AR — which offers similar benefits to VR in memory retention — and we tested its potential in reaching our learning outcomes. We created several demos and prototypes (outlined in Methodology) to collect student-user feedback on the project's overall perceived effectiveness, along with student attitudes toward engaging with the background of a text like Hamlet to better understand the play itself.

We did find other projects in the humanities that incorporate AR. Ours builds on these, yet it differs pedagogically. Where many of these projects serve as showcases for what the technology can accomplish, we planned to tie our work directly to traditional learning outcomes for literature classes, particularly the ability to identify and analyze historical contexts. Our aim echoes Hirsch:

[T]o bracket pedagogy in critical discussions of the digital humanities or to completely exclude it from these discussions reinforces an antagonistic distinction between teaching and research, in which the time, effort, and funding spent on the one cannibalizes the opportunities of the other (5).

Oftentimes new technologies enter the classroom merely because they exist. Teachers use them to catch students' attention (a noble cause, no doubt), but those technologies do little else to aid learning. Our project, however, focuses on reading and our primary goal was getting students to engage with the text, not just the technology. Specifically, we sought to determine whether AR could encourage engaging with the text more effectively than film clips. In the forthcoming pages we will explicate the process of designing a learning application for mobile devices from both technological and pedagogical standpoints. We encountered several unexpected results in our tests, and discovered new pathways to teaching Shakespeare's plays to, primarily, non- 
English majors in introductory literature courses. Using feedback from over 200 students, as well as dozens of instructors, we developed a finished prototype that represents their input and contributes to both research in Shakespeare and teaching with technology.

\section{Text Selection: Why Hamlet?}

We chose Hamlet as our source text for two reasons. First, for its ubiquity on college syllabi at our institution and others across the United States. Also, we found Hamlet causes difficulty for student-readers and instructors wanting to teach it. As one researcher points out, " $89 \%$ of respondents consider[ed] their students at best adequately and often poorly prepared for their [Shakespeare] studies" (Thew 3). We saw a great opportunity to intervene with technology, which has had an influence on Shakespeare pedagogy over the last decade. ${ }^{3}$ Hamlet provides an excellent opportunity for student analysis if the initial barrier to reading is mitigated. Hugh Richmond notes the complexity and uncertainty of Hamlet is like "a gigantic Rorschach test which can be interpreted any way one wants" (Richmond). Though it offers interpretive freedom,

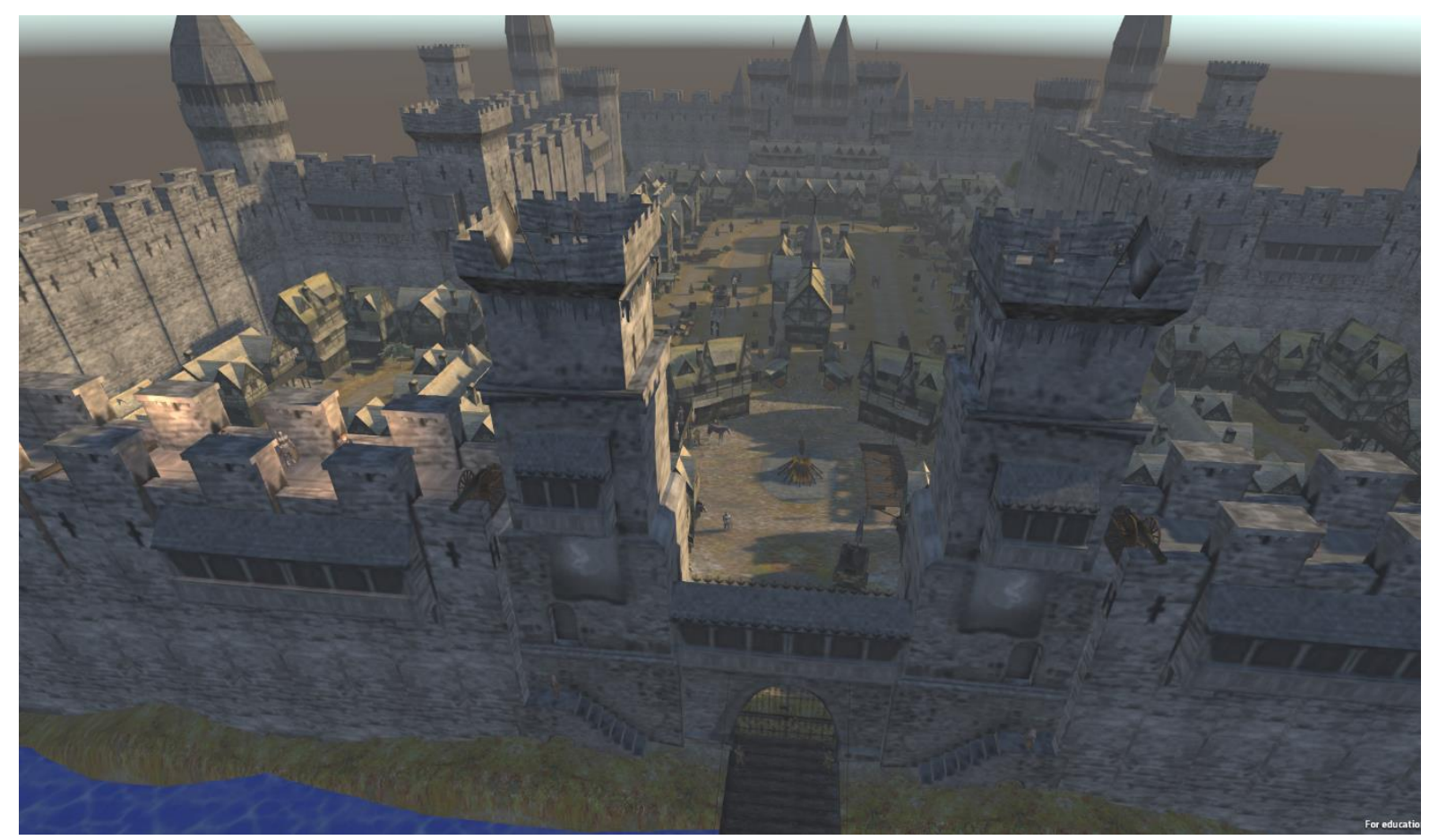

Figure 2. A top view of in-game Elsinore Castle. This image illustrates the compromise between historically accurate and visually appealing graphics. 
for those inexperienced in analysis this can create more perceived difficulty. We began our project with the hopes of letting such students come to conclusions about a small part of the play and then seek the necessary textual references to substantiate their views. Instead of an instructor offering a pre-digested analysis via lecture or through references to online resources, students could come to the meaning on their own.

A primary concern and focus of our project centered on the achievement of actual learning outcomes. We chose the identification of historical and cultural contexts because, as one expert notes, most instructors queried in studies about teaching Shakespeare "felt that the main problems concerned students' lack of linguistic, historical and cultural knowledge" (Thew 7). ${ }^{4}$ Having identified our learning outcomes, we then investigated the text for a small area where this could be explicated using our application. We settled on the reaction of the guards, of Horatio, and especially of Hamlet, to the ghost's appearance. The existence of the ghost in Denmark represents historical and cultural markers, and can serve as an opportunity to illustrate why Bernardo and Marcellus appear nervous at the start of the play; why Horatio, a philosopher and student of the Enlightenment, believes in its existence; and why Hamlet responds to hearing the ghost by saying "My father's spirit in arms. All is not well." The existence of the ghost spurs much of Hamlet's actions, but it also serves as an indication of his state of mind, both of which are central to understanding his motivations - particularly regarding his staging of the play within a play (Joughin). Act I Scenes 4-5, then, appeared to best suit our needs, as they included several key moments in the play and, from our experience, students often miss many connections here that can increase their understanding. We focused on the ghost's armor in Scene V and included information within the application that indicates its historical importance.

Our first prototypes included a 3D model of Elsinore Castle, some character models to fill the empty space, and a placeholder for Hamlet and other characters. The central focus was on the ghost, viewable by students in AR, and, in later iterations, students could interact with it and uncover information vital to understanding the implications of it appearing in battle armor. Using metacognitive practices and meta-strategic knowledge (MSK) - which we will discuss later-we prepared students for the goals of the experience and where to offer feedback. Students would interact with this scene on their mobile phone (or one provided if necessary) and provide feedback on the learning experience. 
We changed our design after initial tests (See Findings/Results/Augmented Reality section) because we saw opportunities for improvement. After deliberations, feedback from students, instructors, and others working on AR/VR projects, we decided to add a gaming element to our application. We felt this development would increase student engagement and trigger deeper, problem-solving cognition, further increasing students' understanding of the historical and cultural contexts of our selected scenes.

\section{Literature Review: Digital and Shakespeare Pedagogy}

Our project involved several different research angles. In order to situate our work correctly, we needed to explore digital humanities as they apply to classroom practices. Subsequently, we needed to tie those to Shakespeare pedagogy. Although we did not end up using VR, we researched its implementation in the classroom before rejecting it in favor of AR for reasons we will discuss later; we also researched the implementation of AR. Finally, we decided to make a game out of our application. Thus, we needed to research game studies as they pertain to literature instruction and learning outcomes.

\section{Digital Humanities Pedagogy}

As high school English teacher Albert Cavalluzzo says, "we need to have technology work for us, not against us" (Herold). In her introduction to Shakespeare and New Media, Kathleen Rowe states, "Older forms and values provide a vital intellectual framework for the way we use newer media, shaping the needs we bring to the new tools and the opportunities we find in them." Accordingly, we sought to encourage traditional reading through modern technological methods, rather than rely more on the technology because, as another source points out, "The digital world has both strengths and weaknesses and it is through an iterative dialogue with other forms that the digital world has emerged and continues to evolve" (Carson and Kirwan). Our strategy of aligning technology with traditional reading evolves from digital humanities pedagogy, and echoes Bruce R. Smith, noting in his chapter of Shakespeare and the Digital World: Redefining Scholarship and Practice, "digital technology can enrich the here-and-now of vital experience but it cannot substitute for it" (30). By creating an application based on modern technology to foster the art of close reading instead of replacing it, we hope to contribute to this digital evolution with firm grounding in traditional learning outcomes. 


\section{Extended Reality (AR/VR) and Education}

\section{Virtual Reality}

Virtual Reality's impact on learning is well documented (Biocca; Burgess, Maguire and O'Keefe; Clemenson and Stark). Though the bulk of research on VR's effectiveness for learning exists in STEM fields, some humanities projects based on the technology exist. Hamlet 360, from the Folger Library, presents a production of the entire play in VR, giving the viewer options to control the camera and what they see. Though more interactive than traditional videos, this presentation didn't solve our concerns; controlling cameras can fail to yield significant benefits to students needing a bridge to close analysis. Thus, Hamlet 360 would have more value for those experienced with the play. The project also leans more toward replacing reading than encouraging it, as it presents the play in its entirety. To Be With Hamlet presents a performance of Act I Scene IV in VR. This offers increased immersion but suffers from the same issues we found with videos; though users can interact by moving around and 'being there' in a way only VR can provide, it is ultimately passive. There is nothing for the user to actually do. It also succumbs to the resource-intensive demands of the technology — that is, the expense and bulk of the equipment, and the time necessary to set it all up.

We had experience in using VR in the classroom ${ }^{5}$ and found it requires significant investments in time and money. In a traditional classroom, one or two headsets can be used at a time. It takes roughly thirty minutes for each student to put on the headset, calibrate, situate themselves in the environment, engage in the activity, and then pass the headset on to the next user. This means it would take 300 minutes for every student in a small class of twenty to complete the lesson. Some schools have VR labs with several headsets, but this requires a class trip to the lab, if available, or requires holding the lesson outside of class. Even the most affordable VR headsets can cost over 300.00 (USD) which limits such an experience to only those schools who can afford such an investment. Our findings in VR indicated potential benefits, and these same benefits can be realized using AR without the resource cost. Thus, we dismissed VR in favor of AR.

\section{Augmented Reality}

AR has drawn attention as an education aid over the last ten years. Learning with AR increases long-term memory retention when dealing with physical tasks (Valimont, Gangadharan and 
Vincenzi). AR has also been shown to increase student attention, satisfaction in learning, and motivation (Ibanez, Blanca and Delgado Kloos). The efficacy of AR in the classroom has been proven in STEM, and much of the research exists there. The findings of the efficacy of AR for learning show a nearly perfect score. In 55 studies over a five-year period, the success of using AR in education was clearly established (Chen, Liu and Cheng). AR showed an extremely high "suitability for learning" across three studies on an AR application (Kaufmann and Dusner). AR has gained ground in other areas, and there are several digital humanities/AR experiences for readers. However, little research exists on AR's use in the humanities. With an $83 \%$ retention rate for learning with AR (Valimont, et al.; Radu), ${ }^{6}$ we saw an opportunity to break new ground in literature classes and offer students a way to experience dense texts more intimately and with greater understanding and retention.

Janet Murray mused about the future of storytelling in the computer age in Hamlet on the Holodeck, and we found AR projects involving Shakespeare's plays that realize her predictions by delivering modern Shakespeare experiences with modern technology. These projects, like many extended reality humanities works, meld new technology with either performances or readings. However, most become 'digital dioramas', bringing objects from the plays or the Globe Theatre or Shakespeare himself to life digitally. There is opportunity to explore visually, but the user makes no decisions. Our learning outcomes focus on decision-making, and the ability for students to feel part of the learning process. Another, Play the Knave, out of the University of California at Davis, uses AR to help students create a digital performance of the play. We found this an encouraging use of AR technology, but sought something less time-consuming for an inclass exercise. These current projects, groundbreaking as they are, merely showcase AR technology with content from Shakespeare's plays. We sought to increase student agency and wanted a more analytic experience closer to actual reading within our application, with students feeling empowered by the freedom to act. Ideally, students can use the application to investigate motivations and other exterior elements - a more active hermeneutic approach. We hoped to build on these new AR experiences that bring Shakespeare's plays to life by adding more input and output from (student) users who would help us beta test our prototypes. 


\section{Shakespeare Pedagogy}

We centered our research on the teaching of Shakespeare by using technology. Many instructional manuals for teaching Shakespeare "advise teaching [...] through a blend of approaches" (Olive 81), including the use of technology. The Royal Shakespeare Company (RSC), through its Stand Up for Shakespeare manifesto, encourages performance-based pedagogies for introductory courses. The aim of having students "feel Shakespeare belongs to them, that they can $[\ldots]$ explore his work in the most enriching way possible" through active and collaborative work is what guides our research. ${ }^{7} \mathrm{We}$ expand on this aim by using gaming as performance, in that students play a minor character investigating within the spaces between Shakespeare's provided dialogue. This narrative inquisition encourages students to seek the text for answers and enables them to feel more present within the contexts of the play. Students do not just sit and try to absorb the text. Instead, in a physical as well as mental enactment of Reader Response theory, ${ }^{8}$ they help complete the narrative of the text as they move about the room exploring Elsinore Castle with our application. Additionally, the gaming community fosters collaboration and discussion more readily than sitting at a desk, or at home, or in the library attempting to read the work.

The traditional performance model of pedagogy in teaching these plays increases engagement, but is only one tool with limitations. Shy students can feel alienated from the practice, and this strategy requires significant development and class time from instructors, the vast majority of whom are either adjuncts or tenure-track with limited time (Rocklin). Our application can incorporate this performance-based approach, and it meets many of the eight elements of drama Edward Rocklin outlines ${ }^{9}$ while conserving preparation time. Our project has students actively engaging with the play's background using their mobile device. Though we do not create a digital performance of Hamlet, nor do we have students act out parts of the play, our practice follows the framework set by Clara Fernandez-Vara's framework for games as performance. ${ }^{10}$

Many current pedagogies recommend using a wide variety of active-learning approaches to teach Shakespeare's plays. The practice of having students engage hands-on with the material has gained popularity, as noted in the RSC's manifesto and Sarah Olive's (2015) two-decadelong study of Shakespeare pedagogy. Thew points to the concerns among instructors of teaching Shakespeare and offers several active practices as interventions for these. Certainly, 


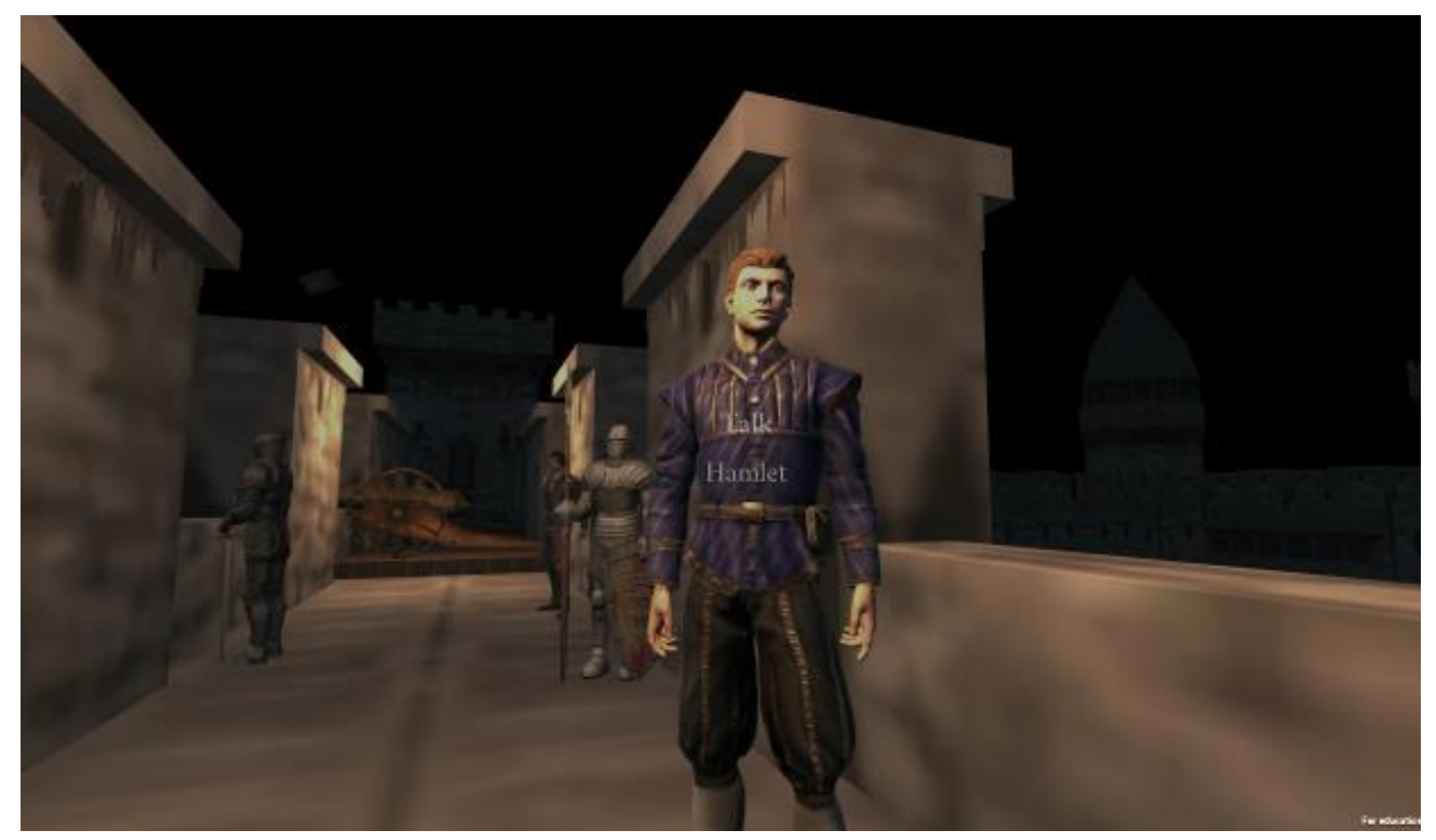

Figure 3. Hamlet in-game, with the "speak" target on his chest revealed by the proximity of the gamer.

technological interventions are not new, and we seek to build on existing strategies by creating an active learning application to help with learning Hamlet (Mello and Less).

\section{Video Game Pedagogy}

We began with AR as our primary technology. After experimenting with it, we sought a way to make it more goal-based and directed toward our learning outcomes. This prompted us to 'gamify' our application so students would better understand the purpose of the experience. Games are not only goals-based, but they also have a positive effect on learning and also on cognition. Perron and Schröter (2015) outline the cognitive effect of video games on players. We know reading elicits emotions and affect, and video games do the same. Games also have an advantage in terms of access to student attention in that they obviate some students' aversion to reading, especially those in our test group. A game created in an immersive AR environment, based on a text like Hamlet that long has had an emotional impact on its readership, should have a tremendous cognitive effect on students. We designed a prototype that aimed to elicit a sense of presence, engage students cognitively, and create a bridge directly to the text. One way to 
ensure this is to situate the learning within a context, following situated learning theory proposed by Lave and Wenger (1991).

Shakespeare-based games have been developed. For example, Richard III Attacks, a game created by La Picola Familia, presents itself as a Pac-Man-style retro game. Though entertaining and true to its source material, it does not readily deliver the context of the play enough for our purposes, nor does it elicit much in the way of emotion or immersion. The creation of a realistic game environment that mimics Shakespeare's fictional Denmark, or more specifically a version of Elsinore that would elicit the historical milieu of Shakespeare's time, can help students experience immersion and connection to the play. "Students feel "personally embodied' in [a] game. Their actions in the game are intrinsically motivated" (Rosenbaum, Klopfer and Perry). Also, digital games offer the characteristic of representation, presenting characters and scenes in a context via the user's screen (Chen, Liao and Cheng). The game environment, specifically the effect of the user's point of view, can elicit senses of selfrepresentation and interactivity that increase user attention spans, among other benefits (Lim and Reeves). Thus, we can potentially convey an understanding of the contexts of Hamlet through the interactivity and immersion of AR and video games. In addition, students can later unpack their experience of the application in relation to critical lenses with which one might view Hamlet. "They can judge and evaluate the material for a given purpose -critical thinking skills" (Connolly, Stansfield and Hainey).

Traditional narrative games can help clarify key elements of story dissection, and there is a developing list of successes in this regard in literature (Chen, Z., et al.; Colby and Colby; Gee). For the purposes of imparting cultural and historical context, they require significant amounts of time. Narrative games can span thirty hours. We found games in general could help us achieve our goals, just not the typical, hours-long experiences we had attempted to use in previous courses. The mechanism of games as learning tools intrigued us, having researched their efficacy in this purpose (Schmitz, Klemke and Specht; Connolly, Stansfield and Hainey; Stizmann; Girard, Magnan and Ecalle). Thus, we sought to insert students directly into the game experience and give them agency over the learning process. 


\section{Methodology}

\section{Pedagogy}

Our goal in creating this application centers on imparting historical contexts from a small vignette of Hamlet. We focused on the learning outcomes of identifying historical and cultural contexts as we saw the traditional way of teaching these consumes valuable class time. To do this, we needed to base our application on a key scene and prepare students for the learning application through metacognitive practices and meta-strategic knowledge (MSK). ${ }^{11}$ This involved highlighting the goals of the learning session, and informing students of their purpose in the application to investigate the castle and its inhabitants, specifically the ghost.

Metacognitive practices and MSK prepare students for learning and make better use of the class time dedicated to our application.

Of key interest was the incorporation of active learning through our use of technology in place of traditional lectures often used to impart historical and cultural contexts. Student agency remains paramount in our efforts, as "successful 'active learning' educational practices emphasize the importance of the individual's control over learning" (Voss, Gonsalves and Federmeier). Rather than sit passively through a lecture or video presentation, students could actively learn while using their mobile devices. This builds on the RSC's call for more active teaching of Shakespeare's plays and research into the benefits of active learning (Allen and Baughman; Freeman, Eddy and McDonough; Mello and Less).

\section{Student Feedback}

In order to gather student feedback, we conducted several presentations and demos to showcase our prototype. We collected feedback from over 200 students at our institution. Initially, students interacted with the demo in class, guided by their instructor, in this case the authors. In order to reach a wider audience, two events were held on campus where nearly 80 students attended. Our test group consisted of primarily those in science, technical, engineering and medical (STEM) fields who take introductory literature courses as a core requirement. Of the sample group polled, roughly $18 \%$ found analyzing literature easy, with over $50 \%$ saying it was notably difficult. In another poll regarding perceived difficulty in reading plays like Hamlet, almost half (49\%) pointed to the difficulty they had following complicated plots. Over $80 \%$ of respondents said 
they played games, which falls in line with national statistics showing over $70 \%$ of college-aged people identifying as gamers (Gallarneau).

Student feedback came in two forms. Students vocalized their suggestions in class and at campus events, which were transcribed. Anonymous polling provided students with the opportunity to give more detailed feedback and to comment on discussions held during class and events. Students provided feedback on three iterations of our project. The first was a 3-minute demo that provided a walkthrough of our application, and the models of Elsinore Castle and its inhabitants. Then, students experienced an AR prototype that enabled them to navigate the 3D models of Elsinore Castle and the ghost in his armor. Lastly, we provided two working demos, one an early release that allowed only for exploration of the game world and that enabled students to provide feedback on visuals, controls, and so forth, and the other a finished prototype that included interactions with characters, historical and cultural contexts, dialog, and the opportunity for students to answer questions afterward.

We gathered feedback from instructors and Shakespeare researchers both formally and informally. First, as part of our participation in a National Science Foundation boot camp, we gathered twenty interviews of English professors and Shakespeare researchers on the difficulties

they experienced teaching complex texts, in particular, Hamlet. We also presented at three major conferences (Pacific Ancient and Modern Language Association, Society of Literature, Science and the Arts, and the Digital Pedagogy Institute), where we showcased our prototype at different stages of development, seeking feedback from instructors, scholars, and game experts. Some of the data collected from conferences came via anonymous polling, but the bulk of the feedback came in the form of informal discussions during which we made detailed notes.

\section{Findings/Results}

Technology Application and Results/Feedback: Augmented Reality

Our design centered on AR and its benefits in terms of engagement, immersion and memory retention. The first prototype included an AR demo where students could superimpose a 3D model of Elsinore Castle and its inhabitants on the floor of the classroom and walk around within it. Students used their own mobile phones for this test, following a provided link to download our model using the Kubity Go application. We wanted to recreate the classroom experience as closely as possible, in order to identify potential problems. We sought the conservation of class 


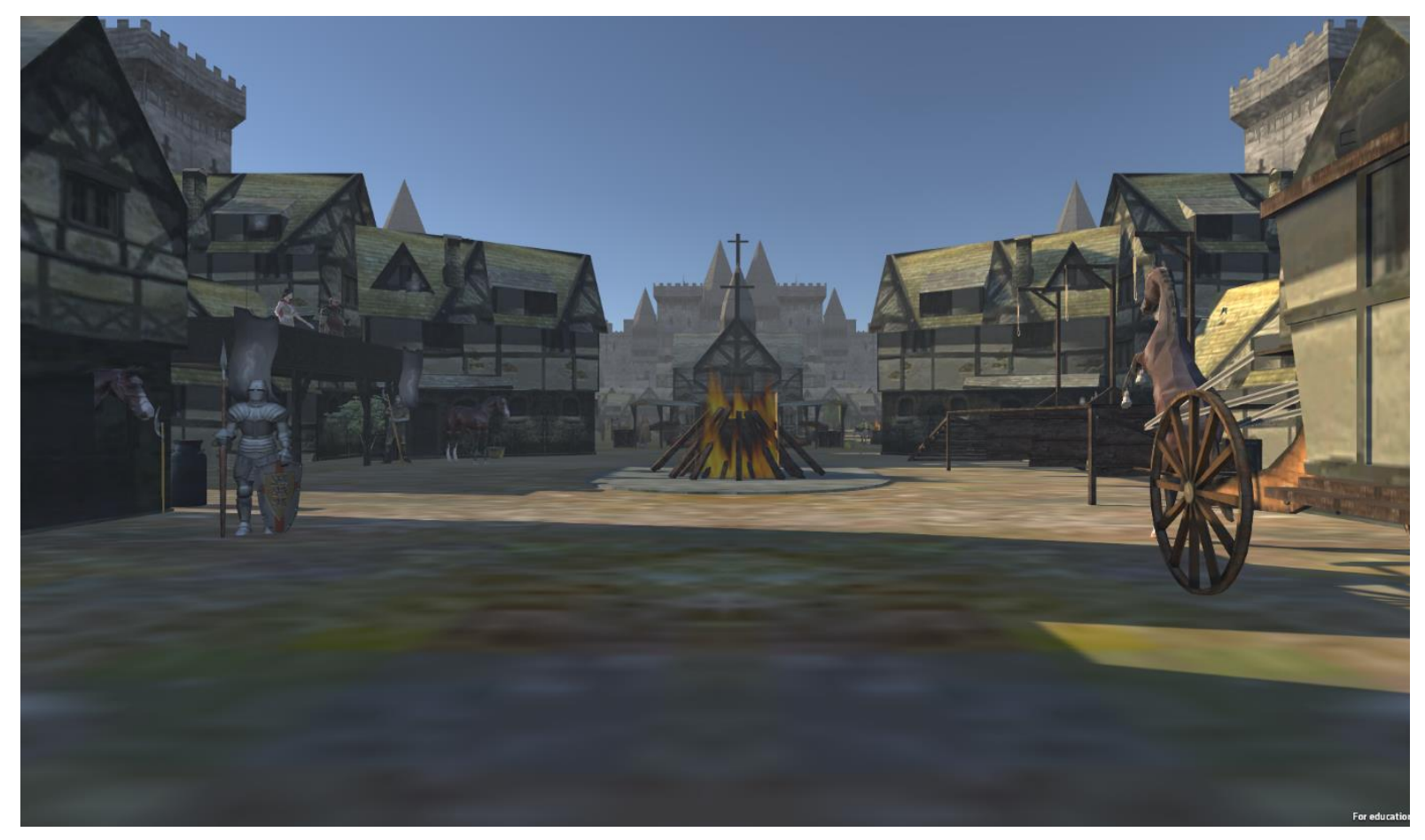

Figure 4. The courtyard of the castle. Players can navigate within a certain radius. We restricted freedom to make the game more linear and less time-consuming, in order to allow for clear objectives and time for class discussion, respectively.

time by having students learn historical contexts on their own (a flipped class format). For the most part, the installation of the application went smoothly, but some students experienced technological issues. This led to their peers assisting them or sharing their mobile device, which promoted collaboration in the classroom.

While observing the installation process, it became clear that students felt protective of their phones. Many hesitated to download the application, and a small number abstained, choosing to use a peer's device instead. Unlike most other classroom technologies (smart screens, desktop computers, etc.) those that involve users' personal devices can elicit protective behavior, which necessitates further consideration. This impediment is an example of how, in attempting to remove traditional barriers to reading, we can possibly suffer from unforeseen modern obstructions. Students identify with their phones on many levels, ${ }^{12}$ and thus can choose not to engage with a technology they feel invades a personal space. Students also expressed concern about battery life, something directly tied to AR as it is resource intensive. Polling indicated that students' phones ran hot and that their battery drained quickly. We attributed some 
of this to the Kubity application which requires two different processes to run at the same time, and we do not feel it is representative of how our final application will impact battery life.

Students took some time orienting themselves to AR, and again, more tech-savvy peers stepped in to assist those who were slower to adapt to this technology. In an introductory literature class of twenty-four students (nineteen of whom were pre-med students) AR's benefits became clear. Students liked the interactivity of the technology and appeared immersed in the environment of Elsinore. They stood up, moved around the room, and investigated the castle and ghost. Some struggled with zooming in and out of the model and couldn't find a usable vantage point, but soon corrected this by themselves or with the help of peers. Most expressed a familiarity with the technology. Student engagement remained high in this class, as with others who tested the AR prototype, and they asked questions about the armor and the presentation of the castle. They talked with each other about this, and even though the application did not have text or answers, they learned about the environment and characters through discussion and asking questions of the instructor. The application brought about more class participation than a standard lecture or multimedia presentation on the historical contexts of Hamlet. 'It's a way for students to learn more about [the play] interactive[ly],' was one student response. Several indicated the benefits the application's immersion offered for learning.

Our AR demonstration did illustrate some deficiencies. First, the aforementioned battery issue affected a significant number of students. Informal polling revealed that even students with advanced phones suffered from this. Classroom size is a concern, as students need a considerable area in which to walk around, because the AR application demanded this for the act of exploration. Though having students up and moving about the classroom has clear benefits, based on the research we cited earlier, the possibility of them bumping into each other, or feeling cramped, is an issue. Students expressed some doubt regarding what they were supposed to do, indicating we needed something more than just AR to encourage immersion and engagement. Some complained that they 'couldn't interact with characters' enough or 'it was a little confusing' without more action and direction and it appeared they may bore of this exercise quickly. We knew we wanted to flesh out the concept more, but we hadn't expected students to want a more goal-oriented exercise. This caused us to rethink the purpose of our application in terms of learning outcomes and the technology we would use to deliver them. 


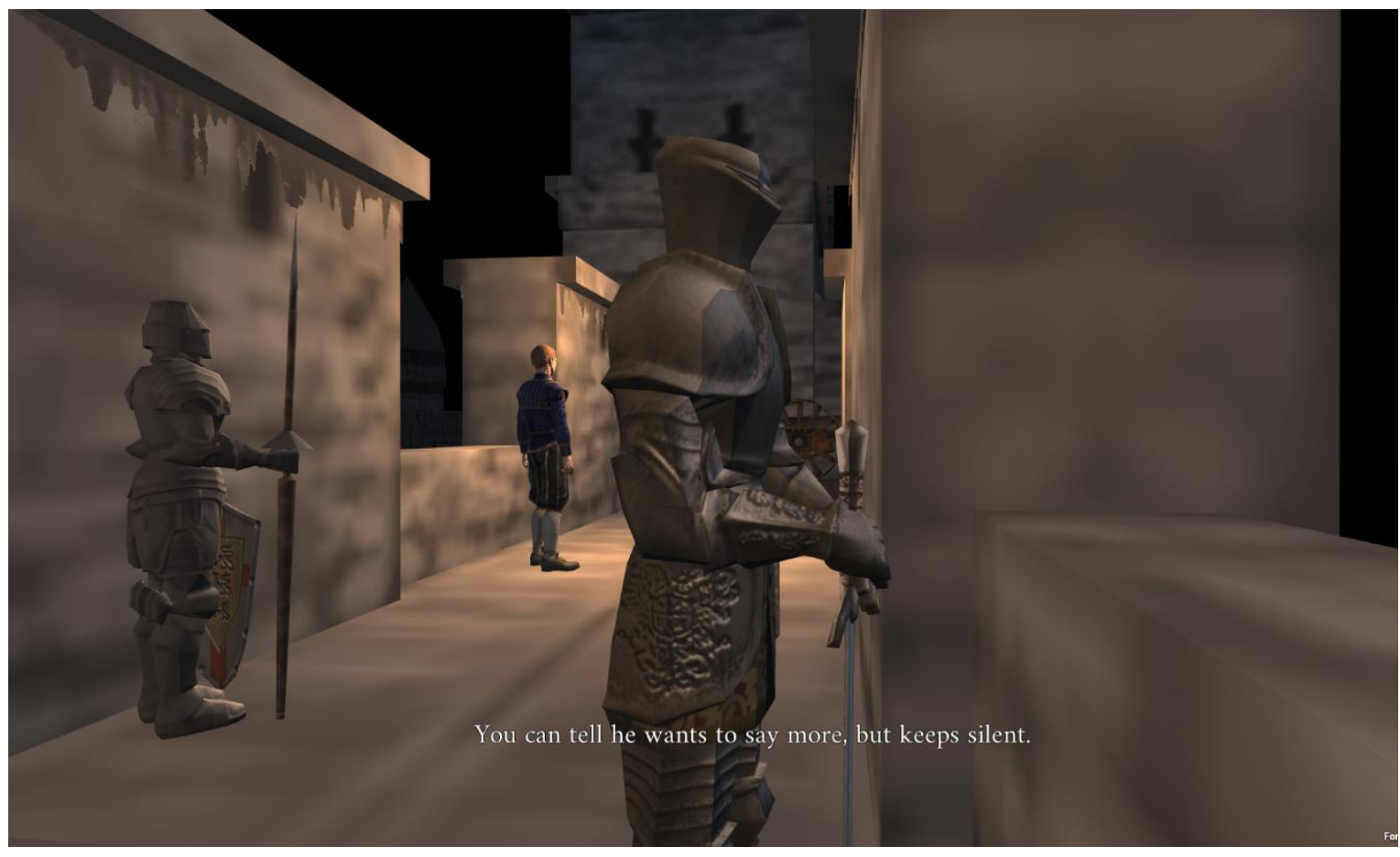

Figure 5. Bernardo's character. Players interact with characters and objects, receiving textual feedback. Again, we paid attention to the effect of the text on player interpretation.

\section{Video Games and Learning}

Having tested our AR prototype and finding its deficiencies greater than its benefits, we decided, as previously mentioned, to add a gaming element. This would enable us to create a more outcome-based approach and engage students while giving them direction and purpose. Our next prototypes included a gaming format and allowed students to navigate around the castle, inspect characters, and get textual feedback. Since "[Hamlet] follows a pattern seen most often in the modern form of the detective story" (Richmond 71), we felt a mystery-style game would best align with the source text and keep students engaged and focused. We could tie the goals of the game with our learning outcomes and have students investigate the circumstance of the ghost's appearance and its implications. Their game play would entail speaking to characters, discovering clues, and making decisions on what the evidence meant in terms of context to the play. We designed demos that highlighted these aspects of our design in order to gauge student interest and feedback. Students experienced a demo movie, a playable model of Elsinore Castle and its inhabitants, and, finally, interacted with characters speaking and a narrator providing 
context. We presented these prototypes and demos on classroom PCs and also allowed for students to download and engage with them on their phones. Given students' general attachment to their mobile devices, we were surprised that most students chose the PCs, expressing preference for playing games on larger screens with a mouse and keyboard for input rather than the smaller screen and controls of a phone. This could also be related to battery issues and the fact that they were very protective of their mobile devices.

These demos and prototypes were well received. Students enjoyed the game element and the ability to explore the castle and its grounds freely. A major element of the feedback revolved around linearity. Students wanted freedom to explore but understood that complete freedom would enable some to get lost exploring rather than achieving goals. We knew this could be an issue and have decided to include direction in the game in the form of a journal or map or other indicator of goal completion. This would also alleviate the concerns from students regarding action. "What will I do in the game?" and variations of this question were repeated often in polling and in discussions. Just as AR by itself cannot help us to reach learning outcomes, a game will not offer much in the way of education unless it has a clear purpose. If we want to impart historical and cultural contexts with our application, we must provide a clear path to these goals. This finding intrigued us, as it serves to validate our initial concept while pointing to ways to improve our design. Most students found this sort of learning application engaging. Prototyperelated problems aside (choppiness, imperfect controls, and so forth), students actively played the game and commented on how they thought this would benefit them in learning about Hamlet before reading it. Many said that learning through a game would make them more comfortable reading the text. This was indicated especially by students who had just finished reading the play and noted that it was significantly difficult.

\section{Pedagogical Implications}

We knew the implications of teaching with technology and discovered that writing the game had pedagogical implications as well. For instance, when we added on-screen dialog and narration, we realized the effect this could have on student interpretation of the contexts. We need to concern ourselves with what the characters and narrator will say and how they say it. A narrator situates the player within the scene with an opening text crawl that explains the situation in fictional Denmark. Used as a precognitive exercise that helps students identify the goals of the 


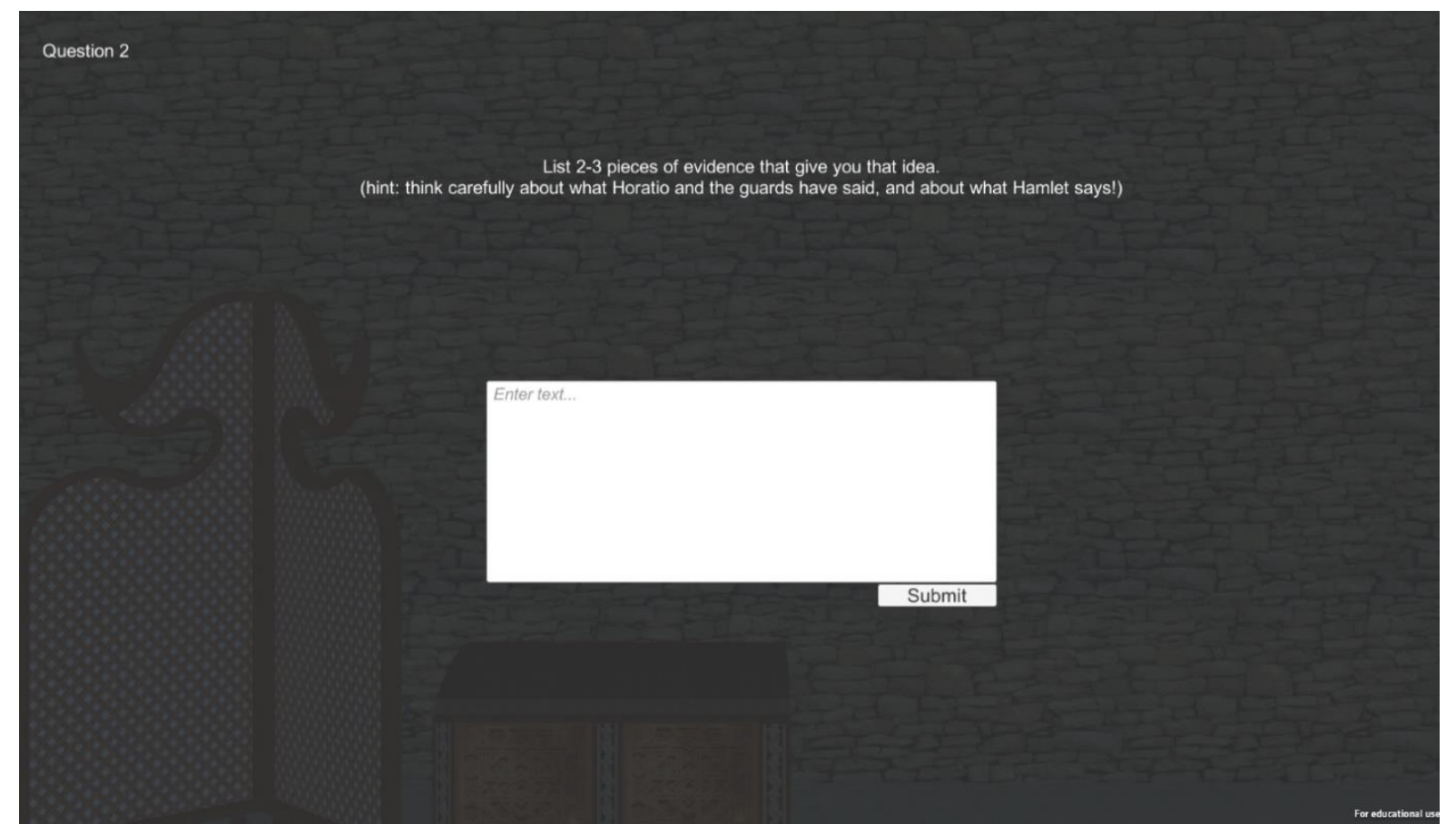

Figure 6. Question and answer prompt after the game. Students provide responses to queries and provide evidence of their choice, mimicking traditional classroom activities.

game, this text might color student interpretations. Much as directors shape their production of a play based on their own goals or biases, educational game designers can influence player perceptions. We attempted to eliminate critical presuppositions during our build but found it impossible. Deciding which schools of literary-critical thought to incorporate requires much consideration, and as we continue to iterate our application, we debate the benefits and drawbacks of including critical views. For the most part, we feel this is best left to the instructors to do when they introduce students to the game, and to any metacognitive exercises they may employ to prepare students for the session.

In the same vein of the RSC's manifesto and several technology and active learning proponents of teaching Shakespeare's plays, our game puts learning in the hands of students and gets them actively performing and participating. The overwhelming majority of students polled regarding this project found it useful and were eager to engage with it. Our test group consisted of no English majors and few with experience in literary analysis, and we discovered that teaching with tools familiar to STEM has distinct benefits for these students. They appeared ready to learn about a topic (a Shakespeare play) similar students often shun. The collaborative 
nature of technology and games increased student participation and brought traditionally silent students into the discussion. From a pedagogical standpoint, the technology of our game and AR can serve as an entryway into close reading and literary analysis, granting agency and access to a diverse group of students.

Our choice of scenes through which to impart our contexts was validated by our testing with students, and discussions with faculty and researchers. Conference feedback also corroborated this. High school students attending a college open house showed keen interest in playing a game before reading a complex text like Hamlet to gain foreknowledge of important contexts. In observing student interaction with the game, we could see that they showed a curiosity for the scene, and it offered ample opportunity for exploration and learning that would help later with reading. Students collaborated with each other during their engagement with the game, and with guidance from an instructor, this can lead to investigation of the text.

\section{Conclusions}

Our prototype and student feedback indicate a 3D/AR game designed to impart historical and cultural contexts from Hamlet can provide valuable learning opportunities. Such a project does need a constant focus on learning outcomes and critical presentation. Our test group's expectations of dense texts and their self-perceived deficiencies in dissecting such works can prevent immersion in the play; however, allowing such students to engage with the context of the play through game-oriented AR bypasses this barrier and allows this segment of students to better understand Hamlet. Consequently, such students can (and did) engage in class discussions more confidently, increasing classroom participation and giving voice to otherwise silent students. We observed a marked increase in student discussion when the game was introduced, versus when using standard lectures or showing of video clips. Just as beneficial to memory retention and successful learning outcomes as VR, AR comes with greater accessibility. Thus, using technologies like video games and AR show promise in the teaching of contexts for dense texts like Hamlet. Our test group of tech-minded students helps illustrate how such technology can make close reading and literary analysis accessible to students outside the humanities.

We also found, however, that caution must be exercised in creating cues and prompts in a learning game: too many and too detailed, and those cues will cause undue influence on a student's interpretation of the story. Yet one must include enough cues and prompts to allow 


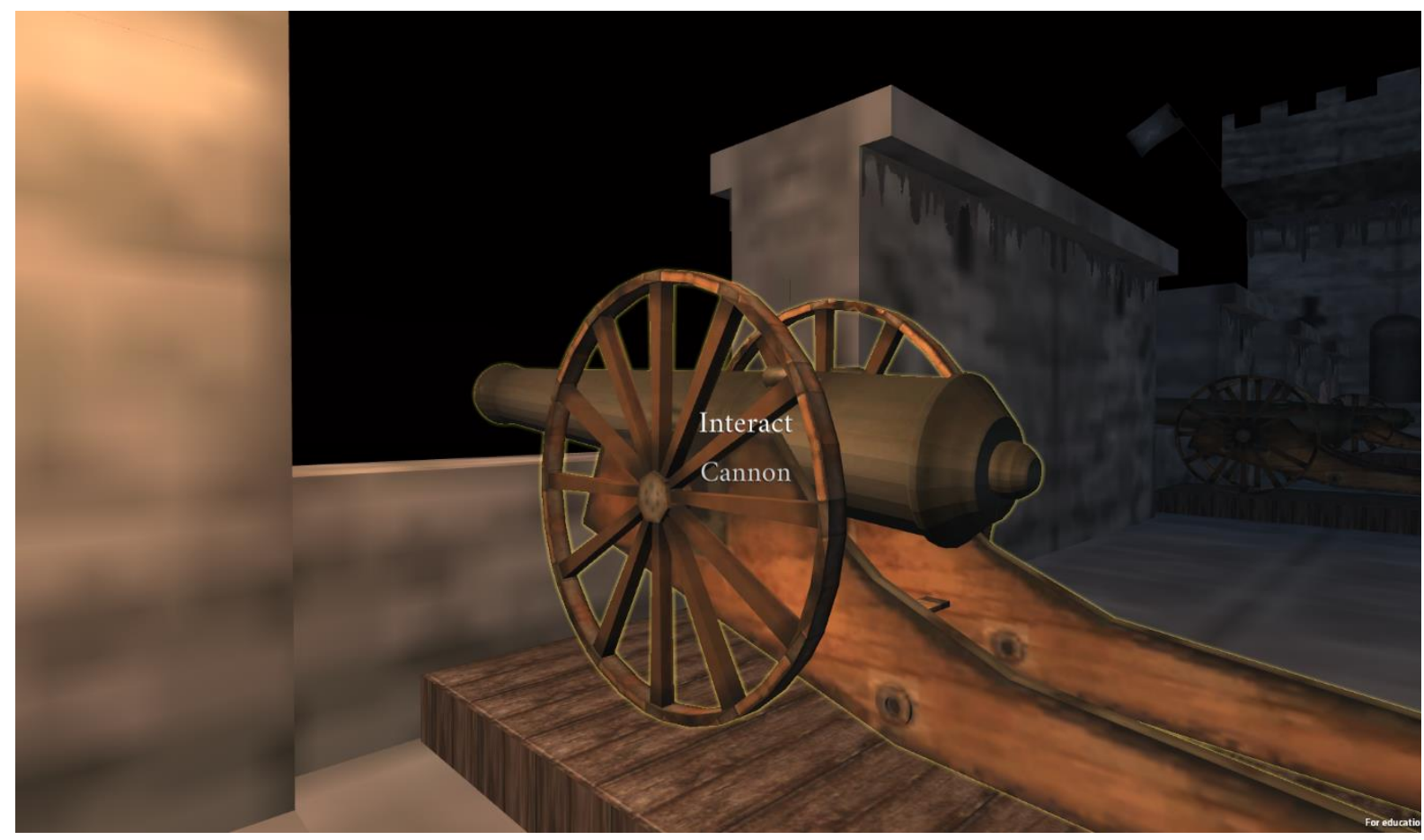

Figure 7. One of the cannons on the rampart of Elsinore. Players interact with objects to gather evidence for their analysis of Hamlet's sanity. The cannons play an important role in the context of the play.

users to make decisions in order to complete the game. Therefore, we paid close attention to how we worded our text in-game, how we presented fictional Denmark, and other areas so as not to lead students to any one interpretation. Also, rather than choose a distinct critical lens through which to view the play and risk over-steering student perceptions, we found it best to attempt to limit critical scopes and allow instructors to guide students in metacognitive practices before using the application. Though this path does have obstacles, we expect that instructors can, through their introduction of students to the game and through metacognitive practices, highlight a particular critical angle that suits their and their students' needs.

Our application (and similar ones) can have an impact on how students view works of literature, how they dissect them, and, ultimately, how they write about them. It can uncover problems in perception that would normally prevent student access to the deeper understandings of the works and help instructors craft classroom environments that better suit the specific needs 


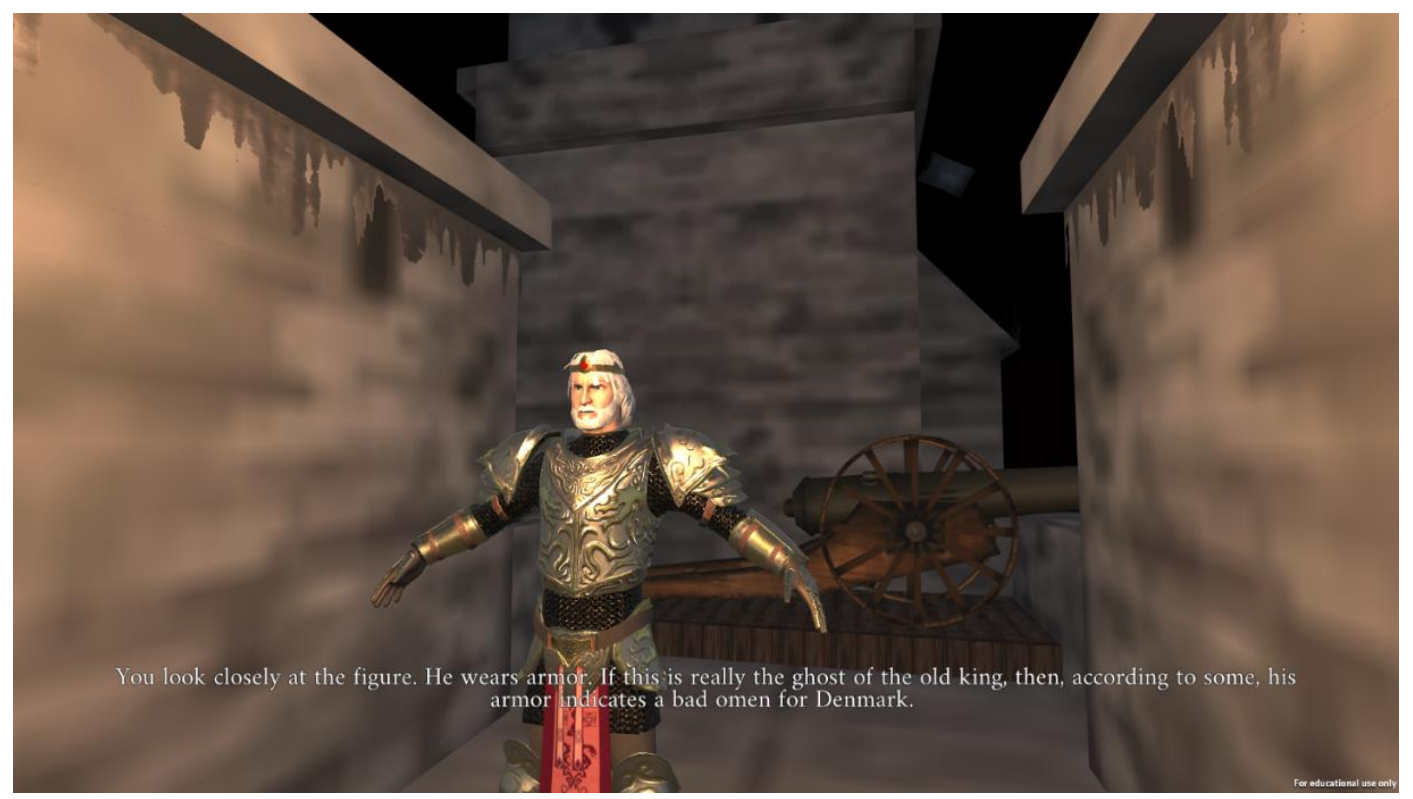

Figure 8. The ghost in his armor. Players, in the prototype, learn of its significance and contexts. This image is an integral part of the game as it delivers a key contextual element of the play.

of individual students. By engaging students more intimately with dense texts, we can give them greater access to the play itself, and possibly, to future literary experiences.

Student feedback played a vital role in our development of this application and its transition from educational application to game. Working with our target audience enabled us to adjust our prototype and design concept and see our project work in real time. What we once thought would enhance students' experience with Shakespeare's works has now opened possibilities for all complex texts and has developed discussions and research points to further college education. We also found using technology in the classroom to enhance the collaborative process: for instance, with tech-minded students offering help to those who had difficulties.

There are other research opportunities that arose through our development of this prototype. How education looks at students' devices, for instance, is an area for further exploration. The impact of a game on student critical thinking serves as another. Most importantly, using game output as a form of student/reader response shows incredible promise and is an area that many in the humanities should consider studying. Other opportunities exist for student collaboration. For instance, student-coders can learn the intricacies about Hamlet through developing and iterating our application further. As we guide the design, student-coders 
understand the reasoning behind contextual decisions and immerse themselves in the text of Hamlet, which may spur further investigation on their own.

\section{Works Cited}

Allen, Peter J. and Frank D. Baughman. "Active Learning in Research Methods Classes Is Associated with Higher Knowledge and Confidence, Though not Evaluations or Satisfaction." Frontiers in Psychology 7 (2016). 12 September 2019. <https://www.ncbi.nlm.nih.gov/pmc/articles/PMC4771750/>.

Biocca, Frank. "The Evolution of Interactive Media Toward 'Being There' in Non-Linear Narrative Worlds." (2001): 1-59.

Burgess, Neil, Eleanor A. Maguire and John O'Keefe. "The Human Hippocampus and Spatial and Episodic Memory." Neuron 35 (2002): 625-641.

Carson, Christie and Peter Kirwan, Shakespeare and the Digital World: Redefining Scholarship and Practice. Cambridge: Cambridge University Press, 2014.

Chen, Peng, et al. "A review of using Augmented Reality in Education from 2011 to 2016." Innovations in Smart Learning (2017): 11-18.

Chen, Z. H., et al. "Influence of game quests on pupis' enjoyment and goal-pursuing in math learning." International Journal of Human-Computer Interaction 32.5 (2012): 373-393.

Clemenson, Gregory D. and Craig E.L. Stark. "Virtual Environmental Enrichment through Video Games Improves Hippocampal-Associated Memory." The Journal of Neurscience 35.49 (2015). <http://www.jneurosci.org/content/jneuro/35/49/16116.full.pdf>.

Colby, Rebekah and Richard Colby. "A Pedagogy of Play: Integrating Computer Games into the Writing Classroom." Computers and Composition 25 (2008): 300-312. <https://www.sciencedirect.com/science/article/pii/S8755461508000406>.

Connolly, Thomas M., Mark Stansfield and Thomas Hainey. "An alternate reality game for language learning: ARGuing for multilingual motivation." Computers \& Education 57.1 (2011): 1389-1415.

Fernandez-Vara, Clara. "The Play's the Thing: A Framework to Study Video Games as Performance." 2009 DiGRA International Conference: Breaking New Ground: Innovation in Games, Play, Practice and Theory. 2009. 
Freeman, Scott, et al. "Active Learning Increases Student Performance in Science, Engineering, and Mathematics." Proceedings of the National Academy of Sciences of the United States of America. 2014.

Gallarneau, Lisa. "2014 Global Gaming Stats: Who's Playing What, and Why?" 16 January 2014. Big Fish Games. 4 July 2017. <http://www.bigfishgames.com/blog/2014-globalgaming-stats-whos-playing-what-and-why/>.

Gee, James Paul. What Video Games Have to Teach Us About Learning and Literacy. New York: Palgrave Macmillan, 2007.

Girard,, C., Annie Magnan and Jean Ecalle. "Serious games as new educational tools: How effective are they? A meta-analysis of recent studies." Journal of Computer Assisted Learning 29.3 (2013). 1 October 2019.

Herold, Benjamin. "Teaching Shakespeare the 21st Century Way." Education Week 36.12 (2016).

Hirsch, Brett D. "</Parentheses>: Digital Humanities and the Place of Pedagogy." Digital Humanities Pedagogies: Practices, Principles and Politics. Ed. Brett D. Hirsch. Open Book Publishers, 2012. 3-33. PDF.

Ibanez, Espiga, Maria Blanca and Carlos Delgado Kloos. "Impact of an augmented reality system on students' motivation for a visual art course." Computers and Education 68 (2013): 586-596.

Joughin, John J. "Shakespeare's Genius: Hamlet, Adaptation, and the Work of Following." The New Aestheticism. Ed. John J. Joughin and Simon Malpas. Manchester: Manchester University Press, 2003. 131-150.

Kaufmann, Hannes and Adreas Dusner. "Summary of Usability Evaluations of an Educational Augmented Reality Application." 2nd International Conference on Virtual Reality. Springer, 2006. <https://www.ims.tuwien.ac.at/publications/tuw-141224.pdf>.

Kim, Bokyeong, Hyungsung Park and Youngkyun Baek. "Not just fun, but serious strategies: Using meta-cognitive strategies in game-based learning." Computers and Education 52 (2008): 800-810. PDF. 1 October 2019.

Lave, Jean and Etienne Wenger. Situated Learning: Legitimate Peripheral Participation. Cambridge: Cambridge University Press, 1991. 
Lim, Sohye and Byron Reeves. "Being in the game: Effects of avatar choice and point of view on psychophysiological responses during play." Media Psychologt 12 (2009): 348-370.

Mello, David and Colleen A. Less. "Effectiveness of Active Learning in the Arts and Sciences." Humanities Department Faculty Publications and Research 45 (2013).

Murray, Janet H. Hamlet on the Holodeck: The Future of Narrative in Cyberspace. New York: The Free Press, 1997. Print.

Olive, Sarah Elizabeth. Shakespeare Valued: Education Policy and Pedgogy 1989-2009. Bristol: Intellect, 2015.

Perron, Bernard and Felix Schroter, Video Games and the Mind: Essays on Cognition, Affect and Emotion. Jefferson: McFarland, 2016.

Play the Knave. Prods. Gina Bloom and Colin Milburn. n.d. 〈http://www.playtheknave.org>. Radu, Iulian. "Augmented reality in education: A meta-review and cross-media analysis." Personal and Ubiquitous Computing 18.6 (2014): 1-11. <https://romisatriawahono.net/lecture/rm/survey/computer\%20vision/Radu\%20\%20Augmented\%20reality\%20in\%20education\%20-\%202014.pdf>.

Richmond, Hugh Macrae. Shakespeare's Tragedies Reviewed. New York: Peter Lang, 2016.

Rocklin, Edward L. "Shakespeare's Script as a Cue for Pedagogic Invention." Shakespeare Quartlery 46.2 (1995): 135-144.

Rosenbaum, Eric, Eric Klopfer and Judy Perry. "On location based learning: authentic applie science with networked augmented realities." Journal of Science Education and Technology 16.1 (2006): 31-45.

Rowe, Katherine. "From the Editor: Gentle Numbers." Shakespeare Quarterly: Shakespeare and New Media Special Edition 61.3 (2010). 10 September 2019. <https://muse-jhuedu.i.ezproxy.nypl.org/article/400347>.

Schmitz, Birgit, Roland Klemke and Marcus Specht. "Effects of mobile gaming patterns on learning outcomes: a literature review." International Journal of Technology Enhanced Learning 4.5-6 (2013).

Smith, Bruce R. "Getting back to the library, getting back to the body." Shakespeare and the Digital World: Redefining Scholarship and Practice. Cambridge: Cambridge University Press, 2014. 14-32. Kindle. 
Stizmann, Traci. "A Meta-Analytic Examination of the Instructional Effectiveness of ComputerBased Simulation Games." Personnel Psychology 64.2 (2011): 489-528. 30 September 2019.

Thew, Neill. "Teaching Shakespeare: A Survey of the Undergraduate Level in Higher Education." Higher Education Academy English Subject Centre, 2006. <https://s3.euwest-2.amazonaws.com/assets.creode.advancehe-documentmanager/documents/hea/private/shakespeare_1568036862.pdf>.

Thompson, Ayanna and Laura Turchi. Teaching Shakespeare with Purpose: A Student-Centered Approach. London: Bloomsbury, 2016. Kindle.

Valimont, R. Brian, et al. "The Effectiveness of Augmented Reality as a Facilitator of Information Acquisition in Aviation Maintenance Applications." Journal of Aviation/Aerospace Education and Research 16.2 (2007): 35-45. $<$ https://commons.erau.edu/jaaer/vol16/iss2/9/>.

Voss, Joel L., et al. "Hippocampal Brain-Network Coordination During Volitional Exploratory Behavior Enhances Learning." Nature Neuroscience 14.1 (2011): 115-123. $<$ http://search.ebscohost.com.arktos.nyit.edu/login.aspx?direct=true\&db=a9h\&AN=5665 $5055 \&$ site $=$ ehost-live \&scope $=$ site $>$.

Zohar, Anat and Adi Ben David. "Paving a clear path in a thick forest: a conceptual analysis of a metacognitive component." Metacognition Learning 4 (2009): 177-195. 2 August 2017.

\section{Notes}

1 Thompson and Turchi (2016) outline the 'modern' students whose "learning habits arise from...technological tools" of the $21^{\text {st }}$ Century and they highlight the importance of addressing the disconnections between activities inside class and out.

${ }^{2}$ See Thew (2006) for one survey example of student attitudes toward reading Shakespeare's plays.

${ }^{3}$ See McCallum as an example for strategies of teaching Shakespeare with technology.

4 Thew's study also indicated how technology can alleviate issues with Shakespeare. See Section 3.

5 In "A (Virtual) Bridge Not Too Far: Teaching Narrative Sense of Place with Virtual Reality", Misak used VR in the classroom and discovered its high cost in terms of price and time.

${ }^{6}$ Although the difference between AR and traditional reading varies, almost all research points to an over $80 \%$ memory retention rate with AR. Radu's studies include dozens of experiments that point to this fact. 7 Taken from Stand Up for Shakespeare: An RSC Manifesto pamphlet. www.rsc.org.uk/standupforshakespeare ${ }^{8}$ On Reader Response theory, see Wolfgang Iser, The Act of Reading (1980). We realize that this tidbit could and perhaps should be much more fleshed out, but the implications of Reader Response theory for gaming and texts are actually so substantial as to be the subject of a completely separate paper; so we will leave it to the future for ourselves or another researcher to delve into this more completely. 
9 Our application conveys the empty space, imparts the presence of actors, the objective form of presentation, the temporal dimension, verbal medium, and the script. See Rocklin (1995).

${ }^{10}$ Fernandez-Vara indicates the three elements of performance that can be applied to video games: dramatic text, performance, and mis-en-scene. A game based on Hamlet incorporates the text of the play and the text created for the game, illustrates the performance of both the computer characters and the player, and, through play, demonstrates the confrontation between the text and performance. This explicates our design goals for a Hamlet game, and readers can reference the article to investigate how Fernandez-Vara illustrates games as performative media, which sets a foundation for our argument on games as performance.

${ }^{11}$ Zohar and David (2009) provide the effects and benefits of using metacognitive practices and learning, and (Kim, Park and Baek) explain the concept of MSK

12 There are many studies which explicate the relationship between user and mobile device. For the purposes of this project, we only want to illustrate a possible problem. Only a few students abstained from the exercise, and it is difficult to estimate how this would extrapolate over a larger audience. 